\title{
The Danish Knee Ligament Reconstruction Registry
}

This article was published in the following Dove Press journal:

Clinical Epidemiology

25 October 2016

Number of times this article has been viewed

\section{Lene Rahr-Wagner \\ Martin Lind \\ Department of Orthopaedic Surgery, Division of Sports Surgery, Aarhus University Hospital, Aarhus, Denmark}

\begin{abstract}
The Danish Knee Ligament Reconstruction Registry was established in 2005 as a web-based nationwide clinical database with the purpose of improving the monitoring and quality of both primary and revision knee ligament reconstructions in Denmark. All primary and revision anterior and posterior cruciate ligament reconstructions as well as collateral ligament and multiligament reconstructions are recorded. Main variables include sex, age, cause of injury, objective ligament instability, and surgical data, such as affected ligament, graft- and implant choice, operation technique among other things. The operating surgeon prospectively collects the data. Hence, detailed preoperative, intraoperative, and 1-year follow-up data are recorded by the operating surgeon using a standardized form and a secured Internet portal. The number of procedures registered in the database each year is $\sim 2,500$ and the first 9 years, in total, 22,775 procedures have been registered. Since the beginning of the database multiple papers have been published in international peer-reviewed journals, improving the knowledge of patients treated with knee ligament reconstruction surgery. This paper reviews the content, organization, and published research from the Danish Knee Ligament Reconstruction Registry.
\end{abstract}

Keywords: ligament reconstruction, anterior cruciate ligament, operation technique, database, graft choice, femoral tunnel drilling, patient-reported outcome measure

\section{Aim of database}

The Danish Knee Ligament Reconstruction registry (DKRR) is a nationwide population-based clinical database that was established in 2005. It has the purpose of monitoring and improving the quality of both primary and revision knee ligament reconstructions in Denmark. ${ }^{1}$

\section{Study population}

In the DKRR, all primary and revision anterior cruciate ligament (ACL) and posterior cruciate ligament reconstructions are recorded as well as collateral ligament and multiligament reconstructions. The DKRR does not register conservative treated ligament injuries. Registrations were started on July 1, 2005. All private $(n=27)$ and public ( $\mathrm{n}=24)$ hospitals report to this register, and registration is compulsory by legislation (https://www.retsinformation.dk/Forms/R0710.aspx?id=173197\&exp=1). ${ }^{1}$

The number of procedures registered in the database each year is $\sim 2,500$ and the first 9 years, in total, 22,775 procedures have been registered. The rate of completeness of registrations in the DKRR has ranged between $85 \%$ and $92 \%$ in the past years and $90 \%$ of all orthopedic departments contribute to the registry. ${ }^{2}$ The registration 
completeness is defined as the number of patients registered with ACL reconstruction in both the DKKR and the Danish National Registry of Patients, divided by the number of patients registered in the Danish National Registry of Patients with ACL reconstruction, in the same period, hence defines the quality of the registration.

The most common ligament reconstruction in the knee is ACL reconstruction. Reconstruction of the ACL is performed for restoration of knee stability in typically young, athletic, and active patients. In the age-group that mainly are prone to ACL injuries (15-40 years), the incidence of surgery is 85 per $100,000 .{ }^{3}$ Approximately two-thirds of patients with ACL injury are treated surgically with ACL reconstruction. Injuries and reconstruction of other knee ligaments, the posterior cruciate ligament and collateral ligaments are more rare and constitutes $<10 \%$ of the all knee ligament reconstructions. ${ }^{1}$

\section{Main variables}

The data collection is web-based and prospectively collected by the operating surgeon. Hence, detailed preoperative, intraoperative, and 1-year follow-up data are recorded by the operating surgeon using a standardized form and a secured Internet portal. ${ }^{1}$

The anamnestic data recorded preoperatively include the unique ten-digit personal identification number (CPR number $),{ }^{4}$ sex, age, date of injury and surgery, previous surgeries to the affected knee, the cause of injury, objective ligament instability including instrumented anterior-posterior laxity, and pivot shift test. The instrumented instability is measured by KT-1000, KT-2000, rolimeter, or other instrumented knee laxity evaluation (Table 1).,

The surgical-related data include: date of surgery, affected ligament, graft- and implant choice, operation technique, meniscal- and chondral damage and management, duration of surgery, complication to surgery, pharmacological antibiotic prophylaxis, and deep venous thrombosis prophylactics (Table 1). Quality of patient care and treatment outcomes is monitored using data from four quality indicators: completeness of 1-year follow-up data, usage of instrumented laxity measurements in preoperative diagnostics, knee laxity 1 year postoperative, and revision rate after 2 years. ${ }^{1,6}$

\section{Follow-up}

In relation to 1-year clinical follow-up, the following data are registered in the DKRR: rate of reoperations, cause of reoperation, pivot shift test, Lachman test, collateral ligament laxity, and instrumented laxity test. Further, the patients report independent subjective scores before surgery and at 1, 5, and 10 years after surgery. ${ }^{1}$ The functional subjective data of each
Table I Database content

\begin{tabular}{|c|c|}
\hline Database & \\
\hline \multirow[t]{6}{*}{ Anamnestic data, preoperative } & Age \\
\hline & Sex \\
\hline & Index side \\
\hline & Previous surgeries \\
\hline & Date of injury \\
\hline & Cause of injury (ADL/sports) \\
\hline \multirow[t]{4}{*}{ Objective data, preoperative } & Pivot shift test \\
\hline & Lachman test \\
\hline & Collateral ligament laxity \\
\hline & Instrumented ACL stability \\
\hline \multirow[t]{12}{*}{ The surgical-related data } & Date of surgery \\
\hline & Duration of surgery \\
\hline & Surgical procedure (ACL, PCL, \\
\hline & revision etc) \\
\hline & Graft choice \\
\hline & Implant choice \\
\hline & Technique for femoral tunnel placement \\
\hline & Meniscal lesion and treatment \\
\hline & Cartilage lesions type and treatment \\
\hline & Surgical complications \\
\hline & Antibiotics prophylaxis \\
\hline & DVT prophylaxis \\
\hline \multirow[t]{7}{*}{ One-year follow-up data } & Complications \\
\hline & Reoperations \\
\hline & Cause of reoperation \\
\hline & Pivot shift test \\
\hline & Lachman test \\
\hline & Collateral ligament laxity \\
\hline & Instrumented ACL stability \\
\hline \multirow[t]{2}{*}{ Patient-subjective data } & KOOS \\
\hline & Tegner score \\
\hline
\end{tabular}

Abbreviations: $A C L$, anterior cruciate ligament; $A D L$, activity of daily living; DVT, deep venous thrombosis; KOOS, Knee Injury and Osteoarthritis Outcome Score; PCL, posterior cruciate ligament.

patient is evaluated using the Knee Injury and Osteoarthritis Outcome Score (KOOS) and Tegner functional score., ${ }^{7,8}$

The KOOS is a knee-specific patient-reported outcome measure (PROM). In recent years, PROMs have gained increased interest as outcome measures and are now identified as important outcome measures after ACL reconstruction. ${ }^{9}$ PROMs are collected via standardized questionnaires designed to measure underlying items that are not directly measurable, such as pain or daily activities. The KOOS ranges from 0 to 100, with higher scores representing better results. The KOOS consists of five subscores: sport and recreation, pain, quality of life, ADL, and symptoms. ${ }^{7}$ These five subscores are evaluated separately. $\mathrm{KOOS}_{4}$ is a patient-reported outcome, computed from the four most responsive KOOS subscores, omitting ADL. ${ }^{10}$

The Tegner score was published in 1985 and is a sportsspecific activity level score, which quantifies activity on a scale from 0 to 10 , with higher scores representing a higher level of activity. ${ }^{8}$ Individuals competing in sports at an elite level have a Tegner score of 10 , individuals participating in 
sports at a recreational level have a Tegner score of 6 , and individuals on a disability pension due to knee problems have a score of 0 . The average Tegner activity level in the normal healthy population is 5.7. Tegner scores after an ACL reconstruction range from 4.5 to $5.0 .^{8}$

\section{Examples of research}

Data from the DKRR have been published in several international peer-reviewed journals (Table 2). Using the unique tendigit CPR number assigned to all Danish citizens at birth, it has been possible to do individual-based research linking data from the DKRR to other clinical and administrative databases, hence provide unique data on vital status, comorbidity, medical use, etc. ${ }^{4,11,12}$ Since the CPR number is consistent through all Danish registries, a precise individual-level data linkage between all Danish registries is possible and hence the CPR number can be used to obtain complete individual follow-up on all patients and data-linkage on a personal level. ${ }^{4}$

Most research on the registry has been on primary ACL reconstructions ${ }^{2,10-14}$ and only one paper to date is published on revision ACL reconstruction and multiligament surgery (Table 2). ${ }^{15}$
The studies published on the DKRR have improved our knowledge of risk factors of sustaining operatively treated ACL injury, information on comorbidity in ACL reconstructed patients, and the failure rates and clinical outcome using different surgical techniques during ACL reconstruction. ${ }^{10-14}$ The results reported on the femoral tunnel drilling technique have triggered international discussions on the potential challenges and implications of initiating a new surgical technique. ${ }^{10}$ A study on the DKRR has also demonstrated that the DKRR enjoys an acceptable completeness of registration and a good registration of key variables although validation on objective measures, the KOOS and the Tegner scores, needs further improvement and validation in the future. ${ }^{2}$ A study on oral contraception use and risk of ACL injury in women indicates that the value of the DKRR may prove to be even greater than previously anticipated owing to the possibility of individual linkage to other important databases such as the Danish National Registry of Patients and the National Danish Prescription Database. ${ }^{12}$ This linkage gives us valuable information on drug use and comorbidity that can be used to investigate the implications of drug use and comorbidity in the future.

Table 2 Papers published on the DKRR in peer-reviewed papers from 2009 to 2015

\begin{tabular}{|c|c|c|c|c|}
\hline Year & Authors & Title & Journal & Reference \\
\hline 2009 & $\begin{array}{l}\text { Lind } M \text {, Menhert F, } \\
\text { Pedersen } A B\end{array}$ & $\begin{array}{l}\text { The first results from the Danish } A C L \text { reconstruction registry: } \\
\text { epidemiologic and } 2 \text {-year follow-up results from } 5,818 \text { knee } \\
\text { ligament reconstructions }\end{array}$ & $\begin{array}{l}\text { Knee Surg Sports } \\
\text { Traumatol } \\
\text { Arthrosc }\end{array}$ & I \\
\hline 2009 & $\begin{array}{l}\text { Granan LP, Forssblad M, } \\
\text { Lind M, Engebretsen L }\end{array}$ & $\begin{array}{l}\text { The Scandinavian ACL registries 2004-2007: baseline } \\
\text { epidemiology }\end{array}$ & Acta Orthop & 5 \\
\hline 2012 & $\begin{array}{l}\text { Lind M, Menhert F, } \\
\text { Pedersen AB }\end{array}$ & $\begin{array}{l}\text { Incidence and outcome after revision anterior cruciate } \\
\text { ligament reconstruction: results from the Danish registry } \\
\text { for knee ligament reconstructions }\end{array}$ & Am J Sports Med & 15 \\
\hline 2013 & $\begin{array}{l}\text { Rahr-Wagner L, } \\
\text { Thillemann TM, } \\
\text { Pedersen AB, Lind M }\end{array}$ & $\begin{array}{l}\text { Increased risk of revision after anteromedial compared } \\
\text { with transtibial drilling of the femoral tunnel during primary } \\
\text { anterior cruciate ligament reconstruction: results from the } \\
\text { Danish Knee Ligament Reconstruction Registry }\end{array}$ & Arthroscopy & 10 \\
\hline 2013 & $\begin{array}{l}\text { Rahr-Wagner L, } \\
\text { Thillemann TM, } \\
\text { Lind M, Pedersen AB }\end{array}$ & $\begin{array}{l}\text { Validation of } 14,500 \text { operated knees registered in the } \\
\text { Danish Knee Ligament Reconstruction Registry registration } \\
\text { completeness and validity of key variables }\end{array}$ & Clin Epidemiol & 2 \\
\hline 2013 & $\begin{array}{l}\text { Rahr-Wagner L, } \\
\text { Thillemann TM, } \\
\text { Pedersen AB, Lind M }\end{array}$ & $\begin{array}{l}\text { Comparison of hamstring tendon and patellar tendon grafts } \\
\text { in anterior cruciate ligament reconstruction in a nationwide } \\
\text { population-based cohort study: results from the danish registry } \\
\text { of knee ligament reconstruction }\end{array}$ & Am J Sports Med & 13 \\
\hline 2014 & $\begin{array}{l}\text { Faunø } \mathrm{P}, \text { Rahr-Wagner } L \text {, } \\
\text { Lind } M\end{array}$ & $\begin{array}{l}\text { Risk for Revision After Anterior Cruciate Ligament Is Higher } \\
\text { Among Adolescents: Results From the Danish Registry of Knee } \\
\text { Ligament Reconstruction }\end{array}$ & $\begin{array}{l}\text { Orthop J Sports } \\
\text { Med }\end{array}$ & 14 \\
\hline 2014 & $\begin{array}{l}\text { Rahr-Wagner L, } \\
\text { Thillemann TM, } \\
\text { Menhert F, Pedersen AB, } \\
\text { Lind M }\end{array}$ & $\begin{array}{l}\text { Is the use of oral contraceptives associated with operatively } \\
\text { treated anterior cruciate ligament injury? A case-control study } \\
\text { from the Danish Knee Ligament Reconstruction Registry }\end{array}$ & Am J Sports Med & 12 \\
\hline 2015 & $\begin{array}{l}\text { Rahr-Wagner L, } \\
\text { Thillemann TM, } \\
\text { Lind M, Pedersen AB }\end{array}$ & $\begin{array}{l}\text { Comorbidities in Patients With Anterior Cruciate Ligament } \\
\text { Reconstruction Compared to Matched Controls Without } \\
\text { Anterior Cruciate Ligament Injury From Danish Registries }\end{array}$ & Arthroscopy & II \\
\hline
\end{tabular}

Abbreviations: ACL, anterior cruciate ligament; DKRR, Danish Knee Ligament Reconstruction Registry. 
These studies on the DKRR has improved our knowledge of ACL injury and ACL reconstructions and will hopefully lead to a better short- and long-term outcome for this group of young patients. Furthermore, the studies have proven that the DKRR can reveal early associations of new treatments on the risk of sustaining revision surgery and instability of the knee. Nevertheless, the mentioned studies do expose some of the weaknesses of national clinical databases such as the DKRR. One of the main weaknesses is the low response rate of objective and PROM follow-up data, and the lack of radiological data to track osteoarthritis development.

\section{Administration and funding}

The database is managed by a steering committee consisting of surgeons and national organization members who geographically represent the country. Centre for Clinical Epidemiology and Biostatistics, North, Department of Clinical Epidemiology, Aarhus University Hospital, Aarhus, Denmark, is responsible for the epidemiological and biostatistical support. The Competence Centre for Clinical Quality and Health Informatics provides the consultancy function for the databases. The DKRR is also supported by the Danish Regions in relation to development of quality and health informatics.

The data are available for research and interested researchers can apply to the steering committee for relevant data. The DKRR provides an annual web-based report not only on the individual hospitals but also on national data, and a steering committee is responsible for optimizing and the management of the database. The competence center for clinical quality and health information performs the data management and epidemiological validation of report.

\section{Conclusion}

This paper describes the content of the DKRR and the results from the database after the first 9 years, the numerous possibilities, and future perspectives.

\section{Acknowledgments}

This paper was funded by the Program for Clinical Research Infrastructure (PROCRIN) established by the Lundbeck Foundation and the Novo Nordisk Foundation and administered by the Danish Regions. The authors acknowledge the knowledge and support from Frank Mehnert and Alma Becis Pedersen from the Department of Clinical Epidemiology and the kind secretarial help provided by Anne Haagen Hjelm at The Competence Centre for Clinical Quality and Health Informatics.

The Danish Rheumatism Association, Aase Einar Danielsens Foundation, Jacob Madsens and Wife Olga Madsens Foundation, Elisabeth and Karl Ejnar Nis-Hanssens
Scholarship, Orthopaedic Research Foundation in Aarhus, and The University of Aarhus, Denmark, have supported the research from the DKRR.

\section{Disclosure}

The authors report no conflicts of interest in this work.

\section{References}

1. Lind M, Menhert F, Pedersen AB. The first results from the Danish ACL reconstruction registry: epidemiologic and 2 year follow-up results from 5,818 knee ligament reconstructions. Knee Surg Sports Traumatol Arthrosc. 2009;17(2):117-124.

2. Rahr-Wagner L, Thillemann TM, Lind M, Pedersen A. Validation of 14,500 operated knees registered in the Danish Knee Ligament Reconstruction Register: registration completeness and validity of key variables. Clin Epidemiol. 2013;5(1):219-228.

3. Granan LP, Bahr R, Steindal K, Furnes O, Engebretsen L. Development of a national cruciate ligament surgery registry: the Norwegian National Knee Ligament Registry. Am J Sports Med. 2008;36(2):308-315.

4. Pedersen CB. The Danish Civil Registration System. Scand J Public Health. 2011;39(7 Suppl):22-25.

5. Granan LP, Forssblad M, Lind M, Engebretsen L. The Scandinavian ACL registries 2004-2007: baseline epidemiology. Acta Orthop. 2009;80(5):563-567.

6. Pedersen AB, Lund B, Jakobsen BW, et al. Dansk Korsbånds Rekonstruktions Register, Arsrapport; 2015. Available from: https://www.sundhed. $\mathrm{dk} /$ content/cms/0/4700_aarsrapport_2015_dkrrfinal22062015.pdf. Accessed March 22, 2016.

7. Roos EM, Toksvig-Larsen S. Knee injury and Osteoarthritis Outcome Score (KOOS) - validation and comparison to the WOMAC in total knee replacement. Health Qual Life Outcomes. 2003;1:17.

8. Tegner Y, Lysholm J. Rating systems in the evaluation of knee ligament injuries. Clin Orthop Relat Res. 1985;(198):43-49.

9. Ahlden M, Samuelsson K, Sernert N, Forssblad M, Karlsson J, Kartus J. The Swedish National Anterior Cruciate Ligament Register: a report on baseline variables and outcomes of surgery for almost 18,000 patients. Am J Sports Med. 2012;40(10):2230-2235.

10. Rahr-Wagner L, Thillemann TM, Pedersen AB, Lind MC. Increased risk of revision after anteromedial compared with transtibial drilling of the femoral tunnel during primary anterior cruciate ligament reconstruction: results from the Danish Knee Ligament Reconstruction Register. Arthroscopy. 2013;29(1):98-105.

11. Rahr-Wagner L, Thillemann TM, Lind M, Pedersen AB. Comorbidities in patients with anterior cruciate ligament reconstruction compared with matched controls without anterior cruciate ligament injury from Danish registries. Arthroscopy. 2015;31:1741-1747.

12. Rahr-Wagner L, Thillemann TM, Mehnert F, Pedersen AB, Lind M. Is the use of oral contraceptives associated with operatively treated anterior cruciate ligament injury? A case-control study from the Danish Knee Ligament Reconstruction Registry. Am J Sports Med. 2014;42(12):2897-2905.

13. Rahr-Wagner L, Thillemann TM, Pedersen AB, Lind M. Comparison of hamstring tendon and patellar tendon grafts in anterior cruciate ligament reconstruction in a nationwide population-based cohort study: results from the danish registry of knee ligament reconstruction. Am J Sports Med. 2014;42:278-284.

14. Faunø P, Rahr-Wagner L, Lind M. Risk for revision after anterior cruciate ligament reconstruction is higher among adolescents: results from the Danish registry of knee ligament reconstruction. Orthop J Sports Med. 2014;2.

15. Lind M, Menhert F, Pedersen AB. Incidence and outcome after revision anterior cruciate ligament reconstruction: results from the Danish registry for knee ligament reconstruction. Am J Sports Med. 2012;40:1551-1557. 
Clinical Epidemiology

\section{Publish your work in this journal}

Clinical Epidemiology is an international, peer-reviewed, open access, online journal focusing on disease and drug epidemiology, identification of risk factors and screening procedures to develop optimal preventative initiatives and programs. Specific topics include: diagnosis, prognosis, treatment, screening, prevention, risk factor modification, ogy \& biostatistical methods, and evaluation of guidelines, translational medicine, health policies \& economic evaluations. The manuscript management system is completely online and includes a very quick and fair peer-review system, which is all easy to use.

Submit your manuscript here: http://www.dovepress.com/clinical-epidemiology-journa| 